\title{
TEMPERATURE REGULATION OF CBC SAMPLES IN CLINICAL LABORATORIES OF KARACHI
}

\author{
Zoobia Zaheeruddin ${ }^{1}$, Aisha Abdul Haq ${ }^{1}$ \&. Humaira Aman ${ }^{2}$ \\ 1. Dow Institute of Medical Technology, DUHS \\ 2. Dow Medical College, DUHS
}

Corresponding author: zoobia_zaheeruddin@yahoo.com

\begin{abstract}
To determine how Labs are maintaining their Laboratory temperatures, To measure the temperature of different clinical laboratories \& to check their controls,to compare temperature affects on Samples \& Controls with normal values \& with each others.In a cross-sectional study, fifteen clinical laboratories in Karachi are examined for observing the standard protocols for running a lab with particular reference to temperature regulation. A questionnaire to the effect is filled and data are statistically analyzed and the following results are obtained. In the 15 labs observed, the mean of complete blood counts performed daily was $1.93 \pm 0.88$. All $15(100 \%)$ labs had a temperature reader. All $15(100 \%)$ labs had an airconditioner installed. Out of these 15 , only 12 were found to be in working condition. Out of 15 laboratories $8(53.3 \%)$ of them perform the sample immediately, 2 of the laboratories $(13.3 \%)$ perform after half an hour, 3 (26.6) perform within 1 hour while $1(6 \%)$ takes more than 1 hour to perform the sample.The finding of this survey showed that some of CBC parameters can be changed with the variation in temperature; therefore it is better to do the CBC test after blood taking as soon as possible. So, the commercial laboratories should be properly registered and their quality standardized.
\end{abstract}

\section{KEY WORDS}

CBC (Complete blood count), RBC indices (Red blood cell Indices), Temperature of storage, Time of storage, Calibration, Temperature, Thermometer, Water baths.

\section{INTRODUCTION}

In clinical laboratories, the cycles of each test starts with the preparation of patient, and continues with biologic sample collection, preparation and incubation the sample in suitable conditions (temperature) and finally finishes by reporting the result.( Cowan, 2005)It is sometimes necessary to redo a test to obtain a reliable result. Sometimes there is a period of time between sample collection and doing or redoing a test(Tarar, 2002) In this situation the stability of the samples is very important. Since blood tests are more common than the other biologic fluids, therefore using the standard methods for sample collection, incubation and the role of environmental factors that affect the blood's indices should be considered( Cowan, 2005). Precise temperature control is an absolute necessity in many clinical settings. In clinical laboratory, many specimens are stored in refrigerators or freezer. Refrigerators \& freezers should b maintained as per manufacturer guidelines \& temperature checks documented(Sarwar, 2006) Accurate calibrated thermometers can be used to verify the accuracy of thermometer used in laboratory. The environmental temperature of the laboratory also raised question about reliability of tests results. The temperature should be maintained at required standard for performing test(Adil,2005; Zhang, 2004 \& Högman, 1999) whether it is the room temperature, temperature of water bath, refrigerators \& air-conditions. A temperature reader should be available to make the regulation of temperature easy for the laboratory workers. Incubators (dry/water) is also used to bring the samples/reagents mixture to proper temperature \& maintain it at a proper temperature for amount of time determined necessary for a reaction to take places( Cowan, 2005).Complete blood count $(\mathrm{CBC})$ is one of the most common and routine laboratory test that is the first step to diagnose an illness and since this test is become easy and quick, it can give valuable information to the physicians( Cowan, 2005)The results of CBC can be affected by different factors such as the temperature and incubation period. In another study it has been demonstrated that incubation of blood samples in different temperature leads to considerable alteration in blood cells and red blood cells (RBCs) indices so there should be a complete understanding of how temperature irregulation may affect the laboratory results(Mujeeb, 2006). It is suggested that every laboratories should have written protocol for temperature regulation $\&$ acceptable temperature controller storage area must be recorded.

\section{METHOD}

The study is a cross sectional survey carried out between September and December 2008. Informed consent was obtained from the laboratory Incharge. Fifteen busy laboratories of Karachi were included, of these 6 were hospital based, 6 commercial and 3 charity laboratories.

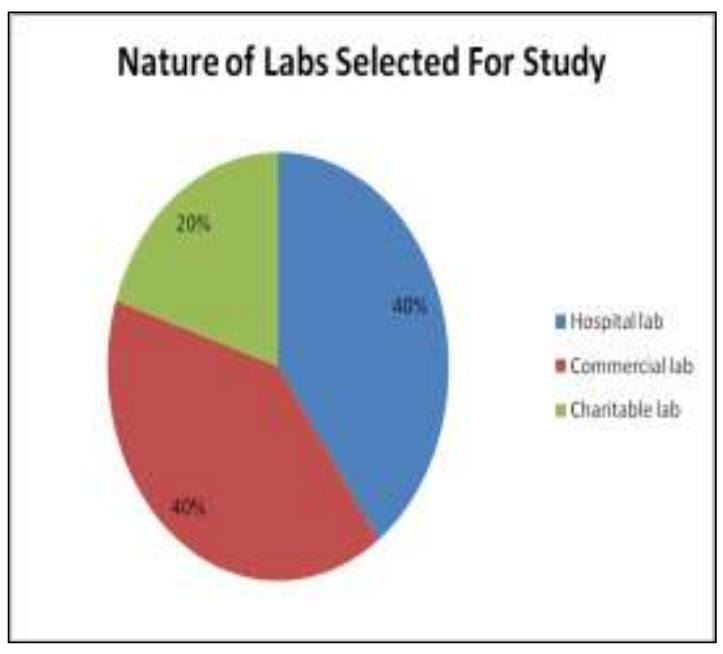

Data was collected through a questionnaire. The laboratories were visited during working hours and practices were observed. Data was analyzed by SPSS version 16 .

\section{RESULTS}

In the 15 labs observed, the mean of complete blood count performed daily was $1.93 \pm 0.88$. All 15 (100\%) labs had a temperature reader. All $15(100 \%)$ labs had an air-conditioner installed. Out of these 15 , only 12 were found to be in working condition. 


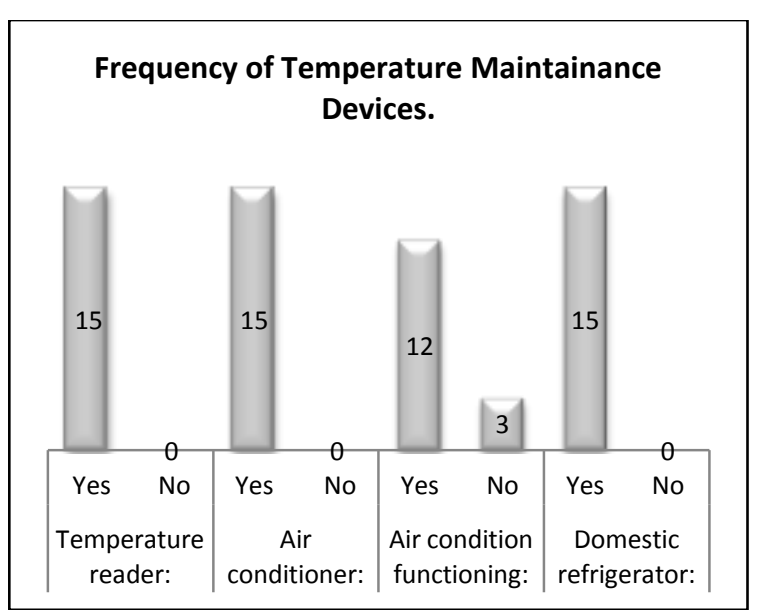

Figure 1: The data shown represents the frequency of temperature maintenance devices.

Out of 15 laboratories $8(53.3 \%)$ of them perform the sample immediately, 2 of the laboratories (13.3\%) perform after half an hour, 3 (26.6) perform within 1 hour while $1(6 \%)$ takes more than 1 hour to perform the sample. Control was available in all (100\%) labs, but this was used daily in $13(86.6 \%)$ labs and $2(13.3 \%)$ of them uses it when problem arises.

Quantity of blood was the same in all the tubes in only $10(66.6 \%)$ labs and in $5(33.3 \%)$ labs quantity was variable. Room temperature in these labs was $21.47 \pm 2.32 \circ \mathrm{C}$.

The purpose of this study was to examine the temperature regulation and standardization practices of clinical laboratories in Karachi. The study suggests that standard operating procedures were being followed in the major clinical laboratories in Karachi. Alternative power supply was available in all $15(100 \%)$ labs(Petersen, 1996) which make sure that the composition of the chemicals and blood samples under analysis give authentic results.

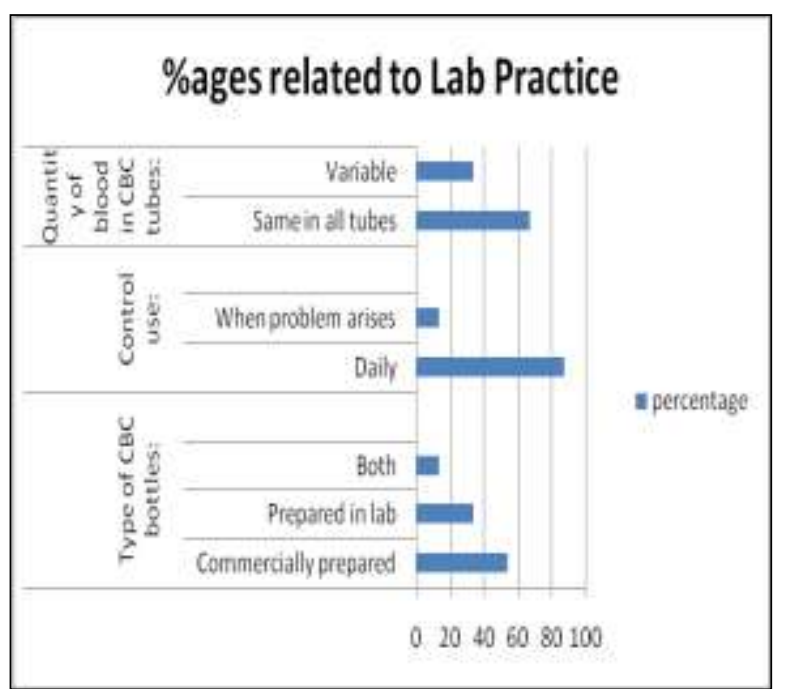

Figure 2: The data shown represents the percentages related to lab practice.

All laboratories should be properly registered and their quality standardized. The results of this study show that most of the laboratories follow standardization procedures for the storage and performance of CBC samples. The results of these labs should be frequently checked and further enhanced time to time to ensure quality of results. $(n=15)$.

Table. Statistics related to lab operation and practices $^{6}$

\begin{tabular}{|l|l|l|}
\hline & Mean \pm & Range \\
& SD & \\
\hline No. of CBC per day & $1.93 \pm 0.88$ & $50-200$ \\
\hline Room temperature (centigrade) & $21.47 \quad \pm$ & $18-25$ \\
& $2.32 \quad$ & \\
\hline
\end{tabular}

Table. Statistics related to lab operation and practices ${ }^{6}(\mathrm{n}=15)$.

\begin{tabular}{|c|c|c|}
\hline & No. & $\%$ \\
\hline \multicolumn{3}{|l|}{ Nature of lab: } \\
\hline Hospital lab & 6 & 40 \\
\hline Commercial lab & 6 & 40 \\
\hline Charitable lab & 3 & 20 \\
\hline \multicolumn{3}{|l|}{ Test performed: } \\
\hline Manual & 0 & 0 \\
\hline Automated & 15 & 100 \\
\hline \multicolumn{3}{|l|}{ Alternate power supply: } \\
\hline UPS & 2 & 13.33 \\
\hline Generator & 5 & 33.33 \\
\hline Both & 8 & 53.33 \\
\hline \multicolumn{3}{|l|}{ Type of CBC bottles: } \\
\hline Commercially prepared & 8 & 53.33 \\
\hline Prepared in lab & 5 & 33.33 \\
\hline Both & 2 & 13.33 \\
\hline \multicolumn{3}{|l|}{ Domestic refrigerator: } \\
\hline Yes & 15 & 100 \\
\hline No & 0 & 0 \\
\hline \multicolumn{3}{|l|}{ Control available: } \\
\hline Yes & 15 & 100 \\
\hline No & 0 & 0 \\
\hline \multicolumn{3}{|l|}{ Control use: } \\
\hline Daily & 13 & 86.66 \\
\hline When problem arises & 2 & 13.33 \\
\hline \multicolumn{3}{|c|}{ Quantity of blood in CBC tubes: } \\
\hline Same in all tubes & 10 & 66.66 \\
\hline Variable & 5 & 33.33 \\
\hline \multicolumn{3}{|l|}{ Co-operation of lab staff: } \\
\hline Freely allowed & 12 & 80 \\
\hline Hesitant & 3 & 20 \\
\hline Not allowed & 0 & 0 \\
\hline
\end{tabular}

\section{DISCUSSION}

In this study the effects of temperature regulation of $\mathrm{CBC}$ samples was evaluated. Our findings showed that some $\mathrm{CBC}$ parameters can be changed with the variation in temperature but Gulati has reported that platelets count did not change up to 4 days incubation at room temperature(Tarar, 2002) Vogelaar et al. that evaluated 304 blood samples of 17-70 years old individuals have reported that incubation blood samples in room temperature for 48 hours did not change the number of RBC, WBC and platelets(Uchida, K., 2000) According to the study of Hirase, the blood cells were stable after one week of Incubation(Gulati, 2002), but in Wood's survey the incubation of samples for 24 hours resulted in the increase of WBC counts(Sarwar, 2006) In Zhang study the cause of platelets increasing explained as increase in whole blood viscosity(Tarar ,2002) Uchida in 2000, Shortland in 1997 and Qi in 2001 have reported that raising the temperature leads to changes in platelet's morphology and movement. (Hirase, Y.,1992; Qi, R.,). It has also been reported in a comprehensive study by Ho et al. that different temperature and time 
of incubation can affect in platelets counts and hemoglobin concentrations (Shortland, A. P.,1997)

\section{CONCLUSION}

The results of this study showed that delay in doing the CBC test can leads to changes in some parameters, therefore the blood samples should not be leaved in the laboratory and the test should be done on blood samples as soon as possible.

\section{REFERENCES}

- Cowan, D. F., Gray, R. Z., \& Campbell, B. C. (2005). Validation of the laboratory information system. In Informatics for the Clinical Laboratory: A Practical Guide (pp. 43-58). Springer New York.

- $\quad$ Adil, M. M., \& Alam, A. Y. (2005). Temperature regulation and standardization practices of Clinical laboratories in Karachi. JPMA. The Journal of the Pakistan Medical Association, 55(2), 88-90. Petersen, P. H., Ricos, C., Stock1, D., Libeer, J. C., Baadenhuijsen, H., Fraser, C., \& Thienpont, L. (1996). Proposed guidelines for the internal quality control of analytical results in the medical laboratory. European journal of clinical chemistry and clinical biochemistry, 34(12), 983-1000.

- Sarwar, I., Abbasi, A. N., \& Islam, A. (2006). Abruptio placentae and its complications at Ayub Teaching Hospital Abbottabad. Journal of Ayub Medical College, Abbottabad: JAMC, 18(1), 27.

- $\quad$ Mujeeb, S. A., Adil, M. M., Altaf, A., Shah, S. A., \& Luby, S. (2003). Infection control practices in clinical laboratories in Pakistan. Infection control and hospital epidemiology, 24(2), 141-142.

- $\quad$ Wood, B. L., Andrews, J., Miller, S., \& Sabath, D. E. (1999). Refrigerated storage improves the stability of the complete blood cell count and automated differential. American journal of clinical pathology, 112(5), 687.

- Zhang, J. N., Wood, J., Bergeron, A. L., McBride, L., Ball, C., Yu, Q., ... \& Dong, J. F. (2004). Effects of low temperature on shear-induced platelet aggregation and activation. The Journal of Trauma and Acute Care Surgery,57(2), 216-223.

- Tarar, M. R., and M. F. Hamid. "A comparison of infection, control practices in pathology laboratories of Government teaching hospitals and private sector in Lahore." Ann King Edward Medcal Coll 8 (2002): 244-6.

- Högman, C. F., Knutson, F., \& Lööf , H. (1999). Storage of whole blood before separation: the effect of temperature on red cell 2, 3 DPG and the accumulation of lactate. Transfusion, 39(5), 492-497.

- Gulati, G. L., Hyland, L. J., Kocher, W., \& Schwarting, R. (2002). Changes in automated complete blood cell count and differential leukocyte count results induced by storage of blood at room temperature. Archives of pathology \& laboratory medicine, 126(3), 336-342.

- $\quad$ Shimizu, T. E. T. S. U. O., Ishikawa, Y. U. K. O., Furuta, A. T. S. U. K. O., \& Fukuda, T. S. U. N. E. O. (1985). Biochemical and membrane functional alterations in red cells during preparation and storage of leukocyte-and platelet-poor red cell suspensions prepared by warm-centrifuge method. The Tohoku journal of experimental medicine, 145(3), 321.

- $\quad$ Hirase, Y., Makatsuka, H., Kawai, T., Horiguchi, S. I., \& Ikeda, M. (1992). Stable blood cell counts after one-week storage at room temperature. Bulletin of environmental contamination and toxicology, 49(4), 504-508.

- $\quad$ NCCLS, Temperature Calibration of Water Baths, Instruments and Temperature Sensors-Second Edition Volume 10 Number 3, Document I2-A2, ISSN 0399-0273 (author name missing)

- $\quad$ Qi, R., Yatomi, Y., \& Ozaki, Y. (2001). Effects of incubation time, temperature, and anticoagulants on platelet aggregation in whole blood. Thrombosis research, 101(3), 139-144.

- $\quad$ Shortland, A. P., Rhodes, N. P., Rattray, A., Black, R. A., \& Williams, D. F. (1997). The effect of temperature and shear rate on platelet aggregation. Journal of Materials Science: Materials in Medicine, 8(12), 887-890.
- $\quad$ Uchida, K., Sakai, K., Ito, E., Hyeong Kwon, O., Kikuchi, A. Yamato, M., \& Okano, T. (2000). Temperature-dependent modulation of blood platelet movement and morphology on poly $(<\mathrm{i}>\mathrm{N}</ \mathrm{i}>$-isopropylacrylamide)-grafted surfaces. Biomaterials, 21(9), 923-929.

- $\quad$ Knutson, F., Lööf, H., \& Högman, C. F. (1999). Pre-separation storage of whole blood: the effect of temperature on red cell 2 , 3-diphosphoglycerate and myeloperoxidase in plasma. Transfusion science, 21(2), 111-115.

- Vogelaar, S. A., Posthuma, D., Boomsma, D., \& Kluft, C (2002). Blood sample stability at room temperature for counting red and white blood cells and platelets. Vascular pharmacology, 39(3), 123-125. 